\title{
Practice of physical activity and dysmobility syndrome in community-dwelling older adults
}

\author{
Vanessa Ribeiro dos Santos ${ }^{1,2, *}$, Tiego Aparecido Diniz ${ }^{3}$, Vitor Cabrera Batista ${ }^{2}$, Ismael Forte Freitas Júnior ${ }^{1,4}$, Luís Alberto Gobbo \\ 'Post-Graduate Program in Movement Sciences, School of Technology and Sciences, São Paulo State University (UNESP), Presidente Prudente, Brazil \\ ${ }^{2}$ Skeletal Muscle Assessment Laboratory (LABSIM), Department of Physical Education, School of Technology and Sciences, São Paulo State University (UNESP), Presidente \\ Prudente, Brazil \\ ${ }^{3}$ Department of Cell and Developmental Biology, Institute of Biomedical Sciences, University of Sao Paulo (USP), São Paulo, Brazil \\ ${ }^{4}$ Department of Physical Education, School of Technology and Sciences, São Paulo State University (UNESP), Presidente Prudente, Brazil
}

The aim this study was to analyze the association between insufficient physical activity and dysmobility syndrome (DS) in community-dwelling older adults. In total, 375 subjects were evaluated aged $\geq 60$ years. For the diagnosis of DS the presence of $\geq 3$ clinical factors was considered: (a) low muscle mass; (b) low muscular strength; (c) low gait speed; (d) high body fat, and (e) osteoporosis. Information relating to the practice of habitual physical activity (HPA) was obtained using a questionnaire and accelerometry. The chi-square test was used to verify the association between HPA and DS and analysis of binary logistic regression to build multiple models. Insufficiently active older adults are approximately 2 times ( $95 \%$ confidence interval, 1.14-3.79) more likely to have DS, independent of body mass index, smoking and ethnicity. The insufficient practice of physical activity is associated with DS in older adults, mainly in women and older.

Keywords: Exercise, Accelerometry, Musculoskeletal disease, Body composition

\section{INTRODUCTION}

Dysmobility syndrome (DS) was recently described, and refers to the aggregation of clinical risk factors for functional disability, such as sarcopenia, osteoporosis and obesity, in addition to a history of falls and fractures. These factors are interconnected with musculoskeletal injuries, since they have the same multifactorial origin, may be caused by inflammation, nutritional deficiencies and physical inactivity (Binkley et al., 2013).

The prevalence of DS is associated with the recurrence of fractures (Iolascon et al., 2015) and an increased risk of death (Looker, 2015), and its occurrence, as well as the clinical factors, increase with advancing age (Clynes et al., 2015; Iolascon et al., 2015; Looker, 2015). This is alarming, since the life expectancy of the world population is increasing considerably (Global Burden of Disease
Study 2013 Collaborators, 2015).

It is known that practice of physical activity contributes to maintaining and increasing muscle mass and strength (Bann et al., 2014; Geirsdottir et al., 2015; Kruger et al., 2016), as well as reducing body fat (BF) (Bann et al., 2014; Foong et al., 2014). Furthermore, it is effective for preventing and treating osteoporosis (Angin et al., 2015; Kemmler et al., 2015; Murtezani et al., 2014) and, consequently, improving the functionality of older adults (Angin et al., 2015; Cooper et al., 2011; Geirsdottir et al., 2015; Murtezani et al., 2014).

In this sense, it is inferred that the practice of physical activity can attenuate the effects or prevent the occurrence of these factors and, consequently, DS. Thus, it is necessary to investigate these aspects, with the objective of preventing the incidence of DS and disability caused by the syndrome in older adults, as well as re-

\footnotetext{
${ }^{*}$ Corresponding author: Vanessa Ribeiro dos Santos

(iD) https://orcid.org/0000-0003-4454-888X

Post-Graduate Program in Movement Sciences, School of Technology and Sciences, São Paulo State University (UNESP), Rua Roberto Simonsen, 305, Bloco 3, Sala 2, CEP 19.060-900, Presidente Prudente, SP, Brazil 
ducing spending on drugs and hospitalizations. Thus, the aim of this study was to analyze the association between insufficient practice of physical activity and DS in community-dwelling older adults.

\section{MATERIALS AND METHODS}

\section{Study design and recruitment of subjects}

The data used in this study refer to the baseline moment of a cohort study, conducted between January 2015 and May 2017 in the city of Presidente Prudente (Southeastern Brazil), in order to investigate the influence of physical activity on sarcopenia, sarcopenic obesity, DS and functional disability in older adults. The sample selection was carried out by convenience sampling.

The minimum sample size for the study was identified using an equation for the correlation coefficient. Thus, using a power of $80 \%$, alpha error of $5 \%$ and correlation coefficient expected between appendicular muscle mass and physical activity of 0.28 (Park et al., 2010), the equation indicated the necessity to assess at least 99 subjects. Additionally, considering a possible sample loss of $100 \%$ over the follow-up, an initial sample of 200 subjects was required.

The following factors were considered as exclusion criteria: living in a long-stay institution; or having a disease which may provide reduced muscle mass, such as cancer, human immunodeficiency virus/acquired immunodeficiency syndrome, tuberculosis and chronic kidney disease. Initial assessments were conducted between the months of January and February 2015.

Subjects aged over 60 years were invited to participate. In the first moment, the recruitment of subjects was performed in two Public Health Services indicated by the Health Municipal Secretary of the city. The invitation and schedule of assessments were performed at the time the participants were waiting for the service or after the end of their appointment. Initially 113 older adults were scheduled; however, of these eight did not attend the assessment.

Subsequently, the invitation was extended to older adults in the general population. The research was published in the local media and in other places of the city with high concentrations of older adults (squares, health clubs, community centers, and other social projects). The assessments were scheduled via phone call. We received 328 calls from older adults interested in participating in the study, of which 38 older adults did not attend the laboratory. In all, 395 participants aged between 60 and 97 years were assessed.

Data collection was conducted in the CELAPAM (Centro de Estudos e Laboratório de Avaliação e Prescrição de Atividade Mo- tora) of the department of Physical Education of School of Technology and Sciences, University Estadual Paulista, UNESP. At the end of this stage, a total of 395 older adults had been evaluated. However, 20 of them did not answer the physical activity questionnaire. Thus, the study sample consisted of 375 older adults aged between 60 and 97 years.

Participants who accepted the invitation to participate signed the "Informed Consent." All protocols were reviewed and approved by the Ethics Committee in Research of School of Technology and Sciences, University Estadual Paulista, UNESP (Process 980.458/2015).

\section{Dysmobility syndrome}

For the diagnosis of DS the presence of three or more of the following clinical factors was considered: (a) low muscle mass; (b) low muscular strength (MS); (c) low gait speed (GS); (d) high BF, and (e) osteoporosis.

\section{Body composition}

The estimation of body composition was performed using Dual Energy X-ray Absorptiometry (DXA) equipment, Lunar brand model DPX-MD, USA, software 4.7, which uses the model of three compartments (lean mass, fat mass, and bone mineral density). This technique allows estimation of the components of body composition, total BF and lean mass and per body segment (upper and lower limbs of both hemibodies).

\section{Muscle mass}

Appendicular muscle mass was measured from the DXA to indicate the low muscle mass, using the skeletal muscle mass index (SMI, in $\mathrm{kg} / \mathrm{m}^{2}$ ), calculated from the ratio of ASM, in $\mathrm{kg}$, and height, in meters squared. For this index, cutoff points of 7.26 and $5.45 \mathrm{~kg} / \mathrm{m}^{2}$ were adopted for men and women, respectively (Baumgartner et al., 1998). Subjects with values of SMI below the cutoff points, according to sex, were considered to have low muscle mass.

\section{Body fat}

High fat was defined as percentage values above $30 \%$ and $40 \%$ of fat mass, measured by DXA, for men and women, respectively (Dufour et al., 2013).

\section{Osteoporosis}

DXA was also used to analyze the bone mineral density at specific sites (total proximal femur and lumbar spine) to identify the 
presence of osteoporosis, with examinations performed following the manufacturer's recommendations. The presence of osteoporosis was defined as a T-score value $\leq-2.5$ (World Health Organization, 2003).

\section{Muscular strength}

Muscular strength (MS) was estimated in $\mathrm{kg}$ from the handgrip, measured using a digital dynamometer, Camry brand, model EH101 (Guangdong, China). The test was performed in duplicate, with subjects sitting in a chair without arm support, shoulders adducted and elbow of the dominant arm flexed at $90^{\circ}$ with the forearm and wrist in a neutral position. The participants were instructed to squeeze the dynamometer as strongly as possible, twice, with an interval of one minute between attempts. The highest value of strength obtained was recorded. Older adults who obtained values below 30 and $20(\mathrm{~kg})$ for men and women, respectively, were classified as low MS (Cruz-Jentoft et al., 2010).

\section{Gait speed}

GS was determined by the 4-m walking test (Guralnik et al., 1994). The participants were instructed to walk at their habitual speed, as if walking inside the house. The longest time $(\mathrm{m} / \mathrm{sec})$ obtained from the two attempts was recorded. Older adults with values below $1.0 \mathrm{~m} / \mathrm{sec}$ were considered as having low GS (Fielding et al., 2011).

\section{Physical activity}

\section{Questionnaire}

Information relating to the practice of regular physical activity was obtained through interviews using the questionnaire developed by Baecke et al. (1982).

The instrument consists of 16 questions and investigates the level of habitual physical activity (HPA) in three areas: occupational (type of occupation and activities during work); physical exercise in leisure (practice of regular physical exercise); and leisure and locomotion activities (watching TV, walking, or cycling in leisure and locomotion).

After application of the instrument it was possible to identify the level of HPA in each area (leisure, occupational, locomotion) and the sum of the scores of each area represent the HPA.

For classification, the formula proposed by Baecke et al. (1982) was used. The level of physical activity of the sample estimated by the total score (HPA) was divided into quartiles. Older adults in quartile 4 (7.37 points) were considered sufficiently active.

\section{Accelerometry}

Motion sensors such as the accelerometer Actigraph GT3X (Actigraph LLC, Pensacola, FL, USA) were also used to estimate the daily practice of HPA. The crude measure from the accelerometer is given in counts (arbitrary measure - the higher the number of counts, the higher the level of physical activity).

The older adults were instructed to use the accelerometers attached to the waist. Participants used the equipment for 5 days and instructions were given prior to use. The accelerometer was required to be used all day during the hours in which the older adults remained awake, being removed only when there was contact with water (personal hygiene or water activities).

For data analysis the specific software ActiLif e6, data analysis software by Actigraph, was used. Only full days of monitoring were included in the database. Consecutive times of zero counts were considered as the period in which the participants were not using the accelerometer and days with less than $10 \mathrm{hr}$ of use were excluded as they had power to increase the variability (Craig et al., 2003). Finally, each participant was required to present at least four full days of monitoring; the usual number of days required to estimate the outcome variables reported in studies with accelerometers.

The intensity of physical activity was analyzed according to the recommendation established by Copeland and Esliger (2009) for the older population. Light physical activity ( $<3.00$ metabolic equivalents $[\mathrm{METs}]$ ) was defined as values equal to or less than 1,040 counts per minute, and physical activities with moderate or vigorous intensity (from 3.00 to 5.99 and 6.00 to 8.99 METs, respectively) were defined as values higher than 1,041 counts.

The sample was stratified according to minutes of physical activity at moderate or high intensity (older adults who did not reach and older adults who reached 30 min of moderate-vigorous physical activity per day) (American College of Sports Medicine, 2009).

During the period of data collection, 202 older adults were randomly selected to use the accelerometer, of these 15 refused. Thus, 187 subjects accepted and took the instrument home to start using the next day, after waking up. However, 30 older adults did not present data for the minimum period of four full days. Thus, 157 assessments were valid (42\% of sample).

\section{Co-variables}

\section{Anthropometric measurements}

Body weight was measured using an electronic scale and height on a fixed stadiometer. The values of weight and height were used 
to calculate the body mass index (BMI, in $\mathrm{kg} / \mathrm{m}^{2}$ ), from the ratio between weight and height squared.

\section{Sociodemographic and behavioral variables}

Information referring to the variables: age, gender, ethnicity, income and smoking were obtained through interviews. The monthly income classification was performed according to tertiles. At the time of collection, 16 older adults refused to report income, therefore, the analysis including this variable was conducted with 359 subjects.

\section{Statistical analysis}

Descriptive statistics were shown from the relative frequency. The percentage values of each variable were associated with the absence or presence of DS using the chi-square test. The Chisquare test was also used to verify the association between HPA in total and in different areas with DS, and binary logistic regression analysis to build multiple models. Statistical analysis was performed using SPSS ver. 17.0 (SPSS Inc., Chicago, IL, USA), and the level of significance was set at $5 \%$. The confidence interval used in this study was $95 \%$.

\section{RESULTS}

The age of the 375 participants (men, $n=114$; women, $n=261$ ) ranged between 60 and 97 years ( $70 \pm 7$ years). The mean age of the men $(72 \pm 7$ years) was significantly higher $(P<0.05)$ than the women ( $70 \pm 7$ years). In contrast, the participation of women in the study was higher compared to men ( $70 \%$ vs. $30 \%)$. The prevalence of DS observed was approximately $27 \%$.

Table 1 presents the general characteristics of the sample according to the prevalence of DS. It was observed that the majority of the older adults with DS were female and aged 70 years or over $(P<0.05)$.

The association between practice of total HPA, HPA in different areas, and DS is shown in (Table 2). A higher prevalence of DS was observed in older adults who were insufficiently active in the area physical exercise in leisure and total HPA.

It was observed that subjects insufficiently active in the area physical exercise in leisure and total HPA are about 2 times more likely to have DS, independent of ethnicity, smoking and BMI $(P<0.05)$. It was also found that the variables gender and age group were statistically significant in the models, with a higher chance for women (odds ratio [OR], 2.18; 95\% confidence interval [CI], 1.24-3.84 and OR, 2.23; 95\% CI, 1.27-3.92) and older
Table 1. General characteristics of the sample according to the presence of dysmobility syndrome

\begin{tabular}{|c|c|c|c|c|}
\hline \multirow{2}{*}{ Variable } & \multirow{2}{*}{ Total (n) } & \multicolumn{2}{|c|}{ Dysmobility syndrome $(n=101)$} & \multirow{2}{*}{$P$-value } \\
\hline & & No & Yes & \\
\hline Gender & & & & 0.014 \\
\hline Male & 114 & $93(81.6)$ & $21(18.4)$ & \\
\hline Female & 261 & $181(69.4)$ & $80(30.6)$ & \\
\hline Age (yr) & & & & 0.018 \\
\hline $60-69$ & 201 & $157(78.1)$ & 44 (21.9) & \\
\hline$\geq 70$ & 174 & $117(67.2)$ & 57 (32.8) & \\
\hline Body mass index $\left(\mathrm{kg} / \mathrm{m}^{2}\right)$ & & & & 0.517 \\
\hline Underweight & 149 & $107(71.8)$ & 42 (28.2) & \\
\hline Eutrophic & 43 & $29(67.4)$ & $14(32.6)$ & \\
\hline Obese & 183 & $138(75.4)$ & $45(24.6)$ & \\
\hline Ethnicity & & & & 0.837 \\
\hline White & 232 & $172(74.1)$ & $60(25.9)$ & \\
\hline Black/brown & 115 & 82 (71.3) & $33(28.7)$ & \\
\hline Asian & 28 & 20 (71.4) & $8(28.6)$ & \\
\hline Income & & & & 0.595 \\
\hline More & 126 & $94(74.6)$ & $32(25.4)$ & \\
\hline Mean & 142 & $103(72.5)$ & $39(27.5)$ & \\
\hline Less & 91 & $65(71.4)$ & $26(28.6)$ & \\
\hline Smoking & & & & 0.064 \\
\hline No & 347 & $249(71.8)$ & $98(28.2)$ & \\
\hline Yes & 26 & $23(88.5)$ & $3(11.5)$ & \\
\hline Osteoporosis & & & & $\leq 0.001$ \\
\hline No & 310 & $247(79.7)$ & $63(20.3)$ & \\
\hline Yes & 65 & $27(41.5)$ & $38(58.5)$ & \\
\hline Body fat (\%) & & & & $\leq 0.001$ \\
\hline Low & 125 & 108 (86.4) & $17(13.6)$ & \\
\hline High & 250 & $166(66.4)$ & 84 (33.6) & \\
\hline $\mathrm{SMI}\left(\mathrm{kg} / \mathrm{m}^{2}\right)$ & & & & $\leq 0.001$ \\
\hline High & 331 & $259(78.2)$ & $72(21.8)$ & \\
\hline Low & 44 & $15(34.1)$ & $29(65.9)$ & \\
\hline Muscular strength (kg) & & & & $\leq 0.001$ \\
\hline High & 247 & $224(90.7)$ & $23(9.3)$ & \\
\hline Low & 128 & 50 (39.1) & $78(60.9)$ & \\
\hline Gait speed (m/sec) & & & & $\leq 0.001$ \\
\hline High & 187 & $174(93.0)$ & $13(7.0)$ & \\
\hline Low & 188 & 100 (53.2) & $88(46.8)$ & \\
\hline
\end{tabular}

Values are presented as number (\%).

SMI, skeletal muscle mass index.

adults aged $>70$ years (OR, 1.73; 95\% CI, 1.07-2.79 and OR, $1.67 ; 95 \% \mathrm{CI}, 1.04-2.70)$ for the practice of physical exercise in leisure and total HPA, respectively (Table 3).

Regarding the presence of clinical factors of DS and intensity of physical activity, it was observed that the practice of insufficient physical activity with moderate and high intensity is associated 
Table 2. Association between the practice of total habitual physical activity and in different areas and dysmobility syndrome in older adults

\begin{tabular}{lccc}
\hline \multirow{2}{*}{ Physical activity } & \multicolumn{2}{c}{ Dysmobility syndrome $(\mathrm{n}=101)$} & \multirow{2}{*}{$P$-value } \\
\cline { 2 - 3 } & \multicolumn{1}{c}{ No } & Yes & \\
\hline Occupational & & & 0.554 \\
Sufficient & $79(75.2)$ & $26(24.8)$ & \\
Insufficient & $195(72.2)$ & $75(27.8)$ & \\
Exercise in leisure & & & 0.012 \\
Sufficient & $94(81.7)$ & $21(18.3)$ & \\
Insufficient & $180(69.2)$ & $80(30.8)$ & \\
Locomotion & & & 0.104 \\
Sufficient & $80(79.2)$ & $21(20.8)$ & \\
Insufficient & $194(70.8)$ & $80(29.2)$ & \\
Total habitual & & & 0.015 \\
Sufficient & $80(82.5)$ & $17(17.5)$ & \\
Insufficient & $194(69.8)$ & $84(30.2)$ & \\
\hline
\end{tabular}

Values are presented as number (\%).

Table 3. Univariate and multiple logistic regression models of the association between insufficient physical activity and dysmobility syndrome in older adults

\begin{tabular}{lcccccc}
\hline \multirow{2}{*}{ Physical activity } & \multicolumn{2}{c}{ Crude } & & \multicolumn{2}{c}{ Adjusted* $^{*}$} \\
\cline { 2 - 3 } \cline { 5 - 7 } & $\mathrm{OR}$ & $95 \% \mathrm{Cl}$ & & $\mathrm{OR}$ & $95 \% \mathrm{Cl}$ \\
\hline Occupational & 1.17 & $0.70-1.96$ & & 1.15 & $0.67-1.98$ \\
Exercise in leisure & 1.99 & $1.16-3.42$ & & 2.03 & $1.16-3.55$ \\
Locomotion & 1.57 & $0.91-2.71$ & & 1.64 & $0.93-2.89$ \\
Total habitual & 2.04 & $1.14-3.65$ & & 2.08 & & $1.14-3.79$ \\
\hline
\end{tabular}

$\mathrm{OR}$, odds ratio; $\mathrm{Cl}$, confidence interval.

*Regression adjusted for sex, age, ethnicity, smoking and body mass index; Hosmer \& Lemeshow test, 0.98 and 0.50 to model regarding the practice of physical exercise in leisure and total HPA, respectively.

with a higher number of clinical factors. The DS clinical factor that was most associated with the practice of physical exercise was MS (Table 4).

Approximately $71 \%$ of the older adults who did not reach the 30 min of physical activity at these intensities had low MS concomitant with DS, $P \leq 0.001$.

Practicing daily physical activity with moderate and vigorous intensity proved to be a protective factor for DS, independent of gender (Table 5).

\section{DISCUSSION}

The main findings of this study were that after assessing physical activity practice in different areas (occupational, physical exercise in leisure and locomotion) and in total, as well as according to the daily amount performed at the recommended intensities, it
Table 4. Association between the practice of physical activity with moderate and vigorous intensity and clinical factors of dysmobility syndrome in older adults

\begin{tabular}{|c|c|c|c|c|c|}
\hline \multirow{2}{*}{ Factor } & \multicolumn{2}{|c|}{ MVPA } & \multirow{2}{*}{$P$-value } & \multirow{2}{*}{$\mathrm{OR}$} & \multirow{2}{*}{$95 \% \mathrm{Cl}$} \\
\hline & Sufficient & Insufficient & & & \\
\hline Osteoporosis & & & 0.455 & & \\
\hline No & 104 (85.2) & $18(14.8)$ & & 1.00 & - \\
\hline Yes & $28(80.0)$ & $7(20.0)$ & & 1.44 & $0.55-3.80$ \\
\hline Body fat (\%) & & & 0.952 & & \\
\hline Low & $39(32.0)$ & $83(68.0)$ & & 1.00 & - \\
\hline High & $11(31.4)$ & $24(68.6)$ & & 1.02 & $0.46-2.30$ \\
\hline $\mathrm{SMI}\left(\mathrm{kg} / \mathrm{m}^{2}\right)$ & & & 0.130 & & \\
\hline High & $104(85.2)$ & $18(14.8)$ & & 1.00 & - \\
\hline Low & $26(74.3)$ & $9(25.7)$ & & 2.00 & $0.81-4.96$ \\
\hline Muscular strength $(\mathrm{kg})$ & & & 0.004 & & \\
\hline High & $93(76.2)$ & $29(23.8)$ & & 1.00 & - \\
\hline Low & $18(51.4)$ & $17(48.6)$ & & 3.03 & $1.38-6.63$ \\
\hline Gait speed (m/sec) & & & 0.775 & & \\
\hline High & $73(59.8)$ & $49(40.2)$ & & 1.00 & - \\
\hline Low & $20(57.1)$ & $15(42.9)$ & & 1.12 & $0.52-2.39$ \\
\hline No. of factors & & & 0.009 & & \\
\hline None & $12(85.7)$ & $2(14.3)$ & & 0.56 & $0.12-2.61$ \\
\hline One & $54(85.7)$ & $9(14.3)$ & & 0.44 & $0.19-1.01$ \\
\hline Two & 32 (76.2) & $10(23.8)$ & & 1.12 & $0.49-2.60$ \\
\hline Three or more & $24(63.2)$ & $14(36.8)$ & & 2.72 & $1.21-6.12$ \\
\hline
\end{tabular}

Values are presented as number $(\%)$.

MVPA, moderate and vigorous intensity physical activity measured by accelerometry; sufficient, $\geq 30$ daily minutes; OR, odds ratio; $\mathrm{Cl}$, confidence interval; SMI, skeletal muscle mass index.

Table 5. Association between the practice of physical activity with moderate and vigorous intensity and dysmobility syndrome in older adults

\begin{tabular}{lccc}
\hline \multirow{2}{*}{ MVPA } & \multicolumn{3}{c}{ Dysmobility syndrome } \\
\cline { 2 - 4 } & No. (\%) & OR & $95 \% \mathrm{Cl}$ \\
\hline 30 min daily & & & \\
No & $14(36.8)$ & 1.00 & - \\
Yes & $24(63.2)$ & 0.39 & $0.17-0.88$ \\
Daily- quartiles & & & \\
1 & $14(36.8)$ & 1.00 & - \\
2 & $11(29.0)$ & 0.71 & $0.27-1.86$ \\
3 & $10(26.3)$ & 0.63 & $0.24-1.68$ \\
4 & $3(7.9)$ & 0.16 & $0.04-0.61$ \\
\hline
\end{tabular}

MVPA, moderate and vigorous intensity physical activity; $\mathrm{OR}$, odds ratio; $\mathrm{Cl}$, confidence interval.

was found that insufficiently active older adults tend to be more likely to have DS.

The total prevalence of DS observed in this study was approximately $27 \%$, being higher for women and older adults aged 70 
years and over. These findings corroborate previous studies (Binkley et al., 2013; Clynes et al., 2015; Looker, 2015).

Physical exercise during leisure time was associated with DS, a higher risk for the syndrome being found in insufficiently active older adults. The activities contained in this section of the questionnaire cover sports practice or regular walks, key activities to reduce BF (Karstoft et al., 2013; Pitanga et al., 2014) and improve functionality (Beavers et al., 2013; Santanasto et al., 2015). Moreover, this section also investigates the practice of physical activity in gyms, composed predominantly of resistance exercises, which are most effective for maintaining and increasing mass (Perreault et al., 2016) and MS (Geirsdottir et al., 2015) and consequently improving balance and GS (Geirsdottir et al., 2015). The practice of sports and other high impact activities are also important for improving bone mineral density, and prevention and treatment of osteoporosis (Angin et al., 2015; Kemmler et al., 2015; Murtezani et al., 2014). This observation reinforces the importance of investigating the association between the syndrome and insufficient practice of physical activity in different areas.

An association was observed between insufficient practice of total HPA and DS, this result is similar to that of Looker (2015), who found that subjects with DS reported less physical activity compared to their peers.

Regarding the intensity of physical activity, the practice of activities with moderate and high intensity for the recommended daily minimum duration (30 min) was associated with the prevalence of clinical factors, with a higher number of factors in insufficiently active older adults. Evidence suggests that such intensities allow higher energy expenditure and are more effective for improving clinical factors of DS (Bann et al., 2014; Foong et al., 2014; Geirsdottir et al., 2015; Kemmler et al., 2015). Thus, it was observed in this study that the practice of physical activity with moderate and high intensity proved to be a protective factor for DS.

Moreover, it was also found that the clinical factor of DS most associated with physical activity in these intensities was MS, with a higher chance of risk of low MS in insufficiently active older adults, as well as which, approximately $71 \%$ of older adults who did not reach the minimum daily recommendation presented low MS and DS concomitantly $(P \leq 0.001)$.

In the study conducted by Lima et al. (2012) with Brazilian older women submitted to a resistance exercise program at the recommended intensities for a 24-week period, the authors found an increase of approximately $17 \%$ in MS. The increase in MS gained from physical training can last longer in people who re- main sufficiently active and contribute to the improvement and maintenance of other clinical factors of DS (Akune et al., 2014; Geirsdottir et al., 2015; He et al., 2016; Solà Serrabou et al., 2014). Thus, the importance of maintaining MS through physical activity for the prevention of the DS is evident, besides all other previously known benefits.

As a caveat, it is noteworthy that the cross-sectional design of this study does not allow the establishment of a cause-effect relationship. However, it is emphasized that there is a gap in the literature regarding studies aiming to verify these aspects in older adults. Another factor would be the investigation of only five of the six suggested DS clinical factors. As strong points of this study, we emphasize the assessment of physical activity in different areas and the use of accelerometers.

Thus, insufficient physical activity is associated with DS in older adults, mainly female and over 70. Preventive measures such as meeting the minimum recommendations for the practice of physical activity throughout life can contribute to the prevention of clinical factors and reduce the risk of DS in older adults.

\section{CONFLICT OF INTEREST}

No potential conflict of interest relevant to this article was reported.

\section{ACKNOWLEDGMENTS}

We would like to thank the Coordenação de Aperfeiçoamento de Pessoal de Nível Superior, Brazil for supporting the study through the award of a scholarship (VRS). We thank Dr. Kong Chen for the use of accelerometers (funded by NIH Z01 DK071013).

\section{REFERENCES}

Akune T, Muraki S, Oka H, Tanaka S, Kawaguchi H, Nakamura K, Yoshimura N. Exercise habits during middle age are associated with lower prevalence of sarcopenia: the ROAD study. Osteoporos Int 2014;25:1081-1088.

American College of Sports Medicine, Chodzko-Zajko WJ, Proctor DN, Fiatarone Singh MA, Minson CT, Nigg CR, Salem GJ, Skinner JS. American College of Sports Medicine position stand. Exercise and physical activity for older adults. Med Sci Sports Exerc 2009;41:15101530.

Angin E, Erden Z, Can F. The effects of clinical pilates exercises on bone 
mineral density, physical performance and quality of life of women with postmenopausal osteoporosis. J Back Musculoskelet Rehabil 2015;28:849-858

Baecke JA, Burema J, Frijters JE. A short questionnaire for the measurement of habitual physical activity in epidemiological studies. Am J Clin Nutr 1982;36:936-942.

Bann D, Kuh D, Wills AK, Adams J, Brage S, Cooper R; National Survey of Health and Development scientific and data collection team. Physical activity across adulthood in relation to fat and lean body mass in early old age: findings from the Medical Research Council National Survey of Health and Development, 1946-2010. Am J Epidemiol 2014; 179:1197-1207.

Baumgartner RN, Koehler KM, Gallagher D, Romero L, Heymsfield SB, Ross RR, Garry PJ, Lindeman RD. Epidemiology of sarcopenia among the elderly in New Mexico. Am J Epidemiol 1998;147:755-763.

Beavers KM, Miller ME, Rejeski WJ, Nicklas BJ, Kritchevsky SB. Fat mass loss predicts gain in physical function with intentional weight loss in older adults. J Gerontol A Biol Sci Med Sci 2013;68:80-86.

Binkley N, Krueger D, Buehring B. What's in a name revisited: should osteoporosis and sarcopenia be considered components of "dysmobility syndrome?". Osteoporos Int 2013;24:2955-2959.

Clynes MA, Edwards MH, Buehring B, Dennison EM, Binkley N, Cooper C. Definitions of sarcopenia: Associations with previous falls and fracture in a population sample. Calcif Tissue Int 2015;97:445-452.

Cooper R, Mishra GD, Kuh D. Physical activity across adulthood and physical performance in midlife: findings from a British birth cohort. Am J Prev Med 2011;41:376-384.

Copeland JL, Esliger DW. Accelerometer assessment of physical activity in active, healthy older adults. J Aging Phys Act 2009;17:17-30.

Craig CL, Marshall AL, Sjöström M, Bauman AE, Booth ML, Ainsworth BE, Pratt M, Ekelund U, Yngve A, Sallis JF, Oja P. International physical activity questionnaire: 12-country reliability and validity. Med Sci Sports Exerc 2003;35:1381-1395.

Cruz-Jentoft AJ, Baeyens JP, Bauer JM, Boirie Y, Cederholm T, Landi F, Martin FC, Michel JP, Rolland Y, Schneider SM, Topinková E, Vandewoude M, Zamboni M; European Working Group on Sarcopenia in Older People. Sarcopenia: European consensus on definition and diagnosis: Report of the European Working Group on Sarcopenia in Older People. Age Ageing 2010;39:412-423.

Dufour AB, Hannan MT, Murabito JM, Kiel DP, McLean RR. Sarcopenia definitions considering body size and fat mass are associated with mobility limitations: the Framingham Study. J Gerontol A Biol Sci Med Sci 2013;68:168-174.

Fielding RA, Vellas B, Evans WJ, Bhasin S, Morley JE, Newman AB, Abellan van Kan G, Andrieu S, Bauer J, Breuille D, Cederholm T, Chandler
J, De Meynard C, Donini L, Harris T, Kannt A, Keime Guibert F, Onder G, Papanicolaou D, Rolland Y, Rooks D, Sieber C, Souhami E, Verlaan S, Zamboni M. Sarcopenia: an undiagnosed condition in older adults. Current consensus definition: prevalence, etiology, and consequences. International working group on sarcopenia. J Am Med Dir Assoc 2011; 12:249-256.

Foong YC, Aitken D, Winzenberg T, Otahal P, Scott D, Jones G. The association between physical activity and reduced body fat lessens with age - results from a cross-sectional study in community-dwelling older adults. Exp Gerontol 2014;55:107-112.

Geirsdottir OG, Arnarson A, Ramel A, Briem K, Jonsson PV, Thorsdottir I. Muscular strength and physical function in elderly adults 6-18 months after a 12-week resistance exercise program. Scand J Public Health 2015;43:76-82.

Global Burden of Disease Study 2013 Collaborators. Global, regional, and national incidence, prevalence, and years lived with disability for 301 acute and chronic diseases and injuries in 188 countries, 1990-2013: a systematic analysis for the Global Burden of Disease Study 2013. Lancet 2015;386:743-800.

Guralnik JM, Simonsick EM, Ferrucci L, Glynn RJ, Berkman LF, Blazer DG, Scherr PA, Wallace RB. A short physical performance battery assessing lower extremity function: association with self-reported disability and prediction of mortality and nursing home admission. J Gerontol 1994;49:M85-94.

He H, Liu Y, Tian Q Papasian CJ, Hu T, Deng HW. Relationship of sarcopenia and body composition with osteoporosis. Osteoporos Int 2016; 27:473-482.

Iolascon G, Moretti A, Giamattei MT, Migliaccio S, Gimigliano F. Prevalent fragility fractures as risk factor for skeletal muscle function deficit and dysmobility syndrome in post-menopausal women. Aging Clin Exp Res 2015;27 Suppl 1:S11-16.

Karstoft K, Winding K, Knudsen SH, Nielsen JS, Thomsen C, Pedersen $\mathrm{BK}$, Solomon TP. The effects of free-living interval-walking training on glycemic control, body composition, and physical fitness in type 2 diabetic patients: a randomized, controlled trial. Diabetes Care 2013; 36:228-236.

Kemmler W, Bebenek M, Kohl M, von Stengel S. Exercise and fractures in postmenopausal women. Final results of the controlled Erlangen Fitness and Osteoporosis Prevention Study (EFOPS). Osteoporos Int 2015;26:2491-2499.

Kruger HS, Havemann-Nel L, Ravyse C, Moss SJ, Tieland M. Physical activity energy expenditure and sarcopenia in Black South African urban women. J Phys Act Health 2016;13:296-302.

Lima RM, Bottaro M, Carregaro R. Effects of resistance training on muscle strength of older women: a comparison between methods. Braz J 
Kinanthrop Hum Perform 2012;14:409-418.

Looker AC. Dysmobility syndrome and mortality risk in US men and women age 50 years and older. Osteoporos Int 2015;26:93-102.

Murtezani A, Nevzati A, Ibraimi Z, Sllamniku S, Meka VS, Abazi N. The effect of land versus aquatic exercise program on bone mineral density and physical function in postmenopausal women with osteoporosis: a randomized controlled trial. Ortop Traumatol Rehabil 2014;16: 319-325.

Park H, Park S, Shephard RJ, Aoyagi Y. Yearlong physical activity and sarcopenia in older adults: the Nakanojo Study. Eur J Appl Physiol 2010;109:953-961.

Perreault K, Courchesne-Loyer A, Fortier M, Maltais M, Barsalani R, Riesco E, Dionne IJ. Sixteen weeks of resistance training decrease plasma heat shock protein 72 (eHSP72) and increase muscle mass without affecting high sensitivity inflammatory markers' levels in sarcopenic men. Aging Clin Exp Res 2016;28:207-214.

Pitanga CP, Pitanga FJ, Gabriel RE, Moreira MH. Association between the level of physical activity and area of visceral fat in postmenopausal women. Rev Bras Med Esporte 2014;20:252-254.

Santanasto AJ, Newman AB, Strotmeyer ES, Boudreau RM, Goodpaster $\mathrm{BH}, \mathrm{Glynn}$ NW. Effects of changes in regional body composition on physical function in older adults: a pilot randomized controlled trial. J Nutr Health Aging 2015;19:913-921.

Solà Serrabou M, López del Amo JL, Valero O. The effect of 24 weeks of moderate-to-high intensity strength training on the elderly. Rev Esp Geriatr Gerontol 2014;49:115-120.

World Health Organization. Prevention and management of osteoporosis: report of a WHO scientific group. Geneva (Switzerland): World Health Organization; 2003. 